\title{
Etnografia segundo Christine Hine: abordagem naturalista para ambientes digitais
}

\section{Adriana Braga}

\section{Resumo}

Christine Hine é uma cientista inglesa que exerce atividades de ensino e pesquisa na Universidade de Surrey, Inglaterra. Adota uma abordagem fortemente interdisciplinar (vai da Biologia à Ciência da Informação e Comunicação), centrandose em metodologias de pesquisa aplicadas aos ambientes online. No Brasil, é mais conhecida por seus livros Virtual Ethnography (Sage, 2000) e Virtual Methods (Berg, 2005). Nesta entrevista, Christine Hine fala sobre sua carreira e influências, bem como sobre a metodologia etnográfica aplicada ao ambiente online e alguns de seus atuais temas de pesquisa.

\section{Palavras-chave}

Etnografia. Metodologia. Internet.
Adriana Braga I adrianabraga@puc-rio.br Professora no Departamento de Comunicação Social da Pontifícia Universidade Católica do Rio de Janeiro (PUC-Rio), pesquisadora do Conselho Nacional de Desenvolvimento Científico e Tecnológico (CNPq) e Editora da Revista E-Compós.
Adriana Braga: Professora Christine Hine, fale-nos um pouco sobre seus passos iniciais na carreira acadêmica. Como decidiu ser acadêmica, onde estudou e quais foram suas principais influências?

Christine Hine: Comecei na carreira acadêmica na área de biologia, não em sociologia. Fiz licenciatura em Botânica na Universidade de Oxford e, depois, Mestrado em Computação Biológica na Universidade de York. A seguir, trabalhei durante um ano em um projeto que produzia mapas de distribuição de espécies, depois decidi voltar a York e fazer doutorado. Interessei-me pelo crescente movimento de uso de bases de dados na biologia para melhorar o acesso à informação relativa à nomeação $e$ taxonomia dos organismos, que adotei como foco de minha tese. Com o tempo, acabei percebendo que estava mais interessada nas pessoas que criavam e usavam essas bases de dados inovadoras em biodiversidade do que em criá-las eu mesma. Muitos dos problemas interessantes e desafiadores nesse campo pareciam centrar-se em como as 
inovações podiam ocorrer dentro do ambiente institucional e dos arranjos sociais da ciência. Graças a alguns úteis conselhos de Mike Mulkay, da Sociologia em York, descobri que a sociologia da ciência oferece alguns recursos teóricos fascinantes para explorar este exato tipo de questão. Fui passando gradualmente da ciência para a sociologia da ciência e tecnologia... onde estou há vinte anos. Meu primeiro trabalho fora da biologia foi com Steve Woolgar, no Centro de Pesquisas em Inovação, Cultura e Tecnologia, que reuniu um grupo realmente instigante de pessoas que estudavam diversos aspectos da ciência e da tecnologia na sociedade, e permitiu que eu tomasse pé em um novo ambiente teórico. Quando a Internet se tornou um fenômeno mainstream, acompanhei, do laboratório para ambientes online, os cientistas que eu estava estudando, o que, por sua vez, levou a um interesse duradouro em adaptar as metodologias da ciência social aos desafios da Internet. Agora trabalho no Departamento de Sociologia da Universidade de Surrey, que me acolhe e dá apoio de forma muito natural devido a sua perícia vasta e profunda nas metodologias sociológicas, e também a seus interesses específicos em estudos sobre novas mídias, ciência e tecnologia e o mundo digital.

\section{Adriana Braga: Durante a sua transição} da biologia para a sociologia da ciência e abordagens metodológicas tais como a etnografia virtual, que autores das áreas de sociologia, comunicação ou mídia você

\section{considera como suas principais} referências teóricas?

Christine Hine: Minhas leituras abrangem bastantes disciplinas: talvez por vir de fora da ciência social, senti que poderia transitar sem me limitar a tradições específicas da ciência social. Além disto, meu primeiro cargo na Universidade de Brunel me levou a ler de forma abrangente, já que o próprio Centro de Pesquisas em Inovação, Cultura e Tecnologia era uma unidade interdisciplinar, e o departamento de ensino a ele associado, o de Ciências Humanas, combinava sociologia, antropologia e psicologia. Retrospectivamente, vejo que muitos dos textos que li eram, de algum modo, sobre produção de conhecimento. Li Steve Woolgar, Science: The Very Idea, sua coletânea sobre Conhecimento e Reflexividade, Bruno Latour, Science in Action; Karen Knorr Cetina, Manufacture of Knowledge; Walter Ong, Orality and Literacy; Joshua Meyrowitz, No Sense of Place; James Clifford e George Marcus, Writing Culture - todos em um espaço de tempo bastante reduzido. Misture todos eles e você sai acreditando firmemente nas tecnologias da informação e comunicação como fenômeno significativo a ser estudado, interessada nos processos de produção de conhecimento que ocorrem em espaços virtuais e reais e em torno deles, e com uma atitude reflexiva em relação a seus próprios processos de produção de conhecimento. Juntando tudo isso, você começa a se aproximar do tipo de abordagem que tentei desenvolver em Virtual Ethnography, com 
inflexões de estudos de ciência e tecnologia, mídia, sociologia e antropologia.

Adriana Braga: Durante décadas, os estudos da Comunicação conceberam os fenômenos comunicacionais a partir de um modelo de mídia no qual existe clara hierarquia entre as corporações de mídia (ou "a mídia") e as pessoas comuns (ou "o público"). Como você vê o equilíbrio de poder entre "a mídia" e "o público" após a difusão das ferramentas de redes sociais?

Christine Hine: Esta é uma grande pergunta, e uma resposta breve realmente não bastaria, mas vou fazer algumas observações. Sem dúvida, o advento das ferramentas de mídia social de fato significa que é muito mais fácil ter voz como pessoa comum, de onde podem resultar algumas formas muito interessantes de novos movimentos sociais. Castells escreveu de forma bastante convincente a respeito de novas formas de poder provenientes das novas capacidades de organização e atuação coletiva, que coexistem com formas convencionais de poder baseadas em formas materiais, de informação e simbólicas de capital, que também retrabalham. Contudo, onde temos visto exemplos significativos de atuação coletiva online, os resultados muitas vezes não têm sido totalmente independentes das corporações de mídia ou outros interesses comerciais. As ferramentas de redes sociais, por exemplo, geralmente são de propriedade de interesses comerciais, e acho um tanto perturbador ver quanto de nosso debate democrático agora passa por canais de mídia que pertencem a corporações, e que esses interesses corporativos, por sua vez, não são independentes de pressão governamental. Este certamente não é o ciberespaço livre e independente da declaração original de John Perry Barlow. Em sentido mais pragmático, é possível a disseminação viral de ideias pela Internet; na prática, porém, muitas ideias são difundidas por serem captadas e promovidas por meio das mídias. A mídia convencional e a Internet estão profundamente entrelaçadas e se baseiam uma na outra em muitos âmbitos, de tal forma que não é possível separar prontamente suas influências. A Internet está imbricada nas mídias e vice-versa. A tal ponto que há um "equilíbrio de poder" entre as corporações de mídia e os públicos que, a meu ver, surge de situações muito específicas e é bastante volátil.

Adriana Braga: A técnica etnográfica foi criada e aplicada historicamente à observação de grupos sociais em copresença física. 0 ambiente digital exige dos pesquisadores uma adaptação das técnicas tradicionais às especificidades da Internet. Numerosos acadêmicos estão tratando dessa adaptação de diferentes maneiras, muitas vezes modificando princípios básicos da etnografia, como o fato de considerar a Internet como fenômeno independente, ignorando práticas cotidianas nas quais a atividade digital está inserida; dedicando 
pouco tempo à observação; desconsiderando falas espontâneas em entrevistas, pois estas costumam ser feitas por e-mail; não dando atenção a um diário de campo; etc. Na sua experiência, quais são os principais cuidados a serem tomados para fazer uma etnografia em ambientes digitais? Como preservar os avanços da teoria metodológica proveniente da tradição antropológica quando esta é aplicada a contextos digitais?

Christine Hine: Concordo com você que muitas versões da etnografia adaptadas a ambientes digitais de fato se afastam muitíssimo dos ideais originais dessa abordagem. De maneira geral, acho que tudo bem quando corresponde à necessidade de uma questão específica de pesquisa, mas é, obviamente, um risco, pois o pesquisador pode não estar fazendo a pergunta mais útil para obter a melhor compreensão. A abordagem mais tradicional da etnografia costuma envolver uma fase muito mais longa, mais intensiva e mais crítica destinada a descobrir a que perguntas o/a pesquisador/a vai responder. Assim, o primeiro aspecto da etnografia tradicional que acho muito útil para a etnografia em meios digitais é dedicar bastante tempo ao processo de familiarização, a olhar em torno e explorar ofenômeno sob todos os ângulos, tentando entender o que ele é, para quem existe e como é vivenciado. Considero este processo muito importante para desenvolver uma ideia das perguntas apropriadas a serem feitas e para alinhar as perguntas que fazemos com nossa noção de o que é esse fenômeno que estamos explorando. Começar diretamente a, por exemplo, fazer uma etnografia de um grupo de discussão online específico corre o risco de saltar esta importante fase de desenvolvimento de uma pergunta apropriada para a qual essa etnografia possa ser a resposta (e de pensar se de fato é prioridade para alguém obter resposta a essa pergunta, em termos práticos ou como parte do desenvolvimento de determinadas orientações teóricas). 0 segundo aspecto fundamental da etnografia de que não abro mão é a reflexividade. Os fenômenos digitais são muito complexos. Existem em múltiplos espaços, são fragmentados e costumam ser temporalmente complexos. Não podemos esperar ter uma vivência de um fenômeno assim apenas "estando presentes ali", porque não sabemos automaticamente onde é "ali", nem como "estar presentes". Mas podemos ajudar a entender os fenômenos digitais tentando adquirir nossa própria experiência autêntica desses fenômenos como etnógrafos inseridos, incorporados, $e$ refletindo constantemente sobre o que sabemos e como o sabemos. Penso que este aspecto da reflexividade - refletir sobre como sabemos o que sabemos sobre uma situação - provavelmente seja a parte mais significativa da etnografia em ambientes digitais. É importante refletir continuamente sobre a maneira como nosso entendimento é plasmado por determinadas abordagens metodológicas, pelo subconjunto de participantes com quem acontece de estarmos interagindo e pelos meios que escolhemos para essas interações. Ao pensar sobre os limites do 
nosso entendimento, podemos também pensar mais criativamente sobre o modo como todos os/ as participantes de fenômenos digitais lidam com as incertezas inerentes às interações sociais online. Perversamente, ao deter-nos nos limites do nosso próprio entendimento, acho que podemos entender algo mais profundo a respeito da natureza das interações online. A reflexividade é a chave, e isto, para mim, está ligado com uma longa tradição de etnografia crítica e reflexiva que existia bem antes de a Internet tornar-se um fenômeno dominante. Este aspecto de fato é perdido em algumas das abordagens mais realistas da etnografia online, que a tratam simplesmente como um modo de obter informações sobre uma realidade préexistente, singular.

\section{Adriana Braga: Considerando que esta} entrevista será publicada em um número especial dedicado a teoria e métodos, eu lhe perguntaria o que você quer dizer com abordagens realistas da etnografia online? Poderia dar exemplos?

Christine Hine: Van Maanen (1988) chama de etnografia realista o estilo de escrita que apresenta as observações etnográficas como fatos relativos a culturas. Cruamente falando, uma etnografia realista trabalharia a partir do ideal de que se pode produzir um relato objetivo da cultura que está sendo estudada, como se esta existisse como entidade singular no mundo. Esse tipo de abordagem coloca o etnógrafo, e suas interpretações, muito em segundo plano e se concentra em evidências documentáveis. Há muitíssimos exemplos disto em estudos online, enfocando, por exemplo, um grupo de discussão online como se este representasse uma cultura discreta, circunscrita - o que é muito tentador quando o grupo online nos apresenta uma versão aparentemente total, arquivada do que essas pessoas fizeram e disseram. Sinto-me muito mais atraída para uma abordagem que frisa as interpretações diversas que podem ser colocadas sobre os fenômenos e que se centram no etnógrafo como construtor ativo da situação de campo e do texto. Assim, podemos decidir centrar-nos em um website online circunscrito e específico, mas isto plasma nossas conclusões de uma determinada maneira, e é útil reconhecer, e explorar, o modo como outras escolhas poderiam ter gerado um resultado muito diferente. Impressionam-me muito os textos recentes de John Law sobre a maneira como os métodos de pesquisa não apenas documentam a sociedade, mas plasmam mais ativamente o que é considerado como sociedade.

Adriana Braga: Os cientistas e acadêmicos talvez tenham sido uma das primeiras categorias profissionais a usar PCs e a Internet todos os dias como recursos em sua vida cotidiana, desde os anos 1980. Ao mesmo tempo, assistimos nas últimas décadas ao ascenso de uma concepção industrial de ciência, às vezes chamada de "produtivismo acadêmico". Em antropologia, este modelo geral de administração acadêmica afetou, 
entre outras coisas, o tempo disponível para fazer trabalho etnográfico de campo - como mostra a expressão "etnografia rápida". Em tempos de "publicar ou perecer", como você avalia a perspectiva de produzir uma etnografia de longo prazo, teoricamente densa e criativa?

Christine Hine: Que pergunta tão difícil para alguém que acaba de voltar de um ano sabático para as alegrias do ensino e da administração! Sério, acho que o tempo para pesquisas de todo tipo está sob pressão; é vital, e ao mesmo tempo muito difícil, defender a importância da "pesquisa lenta" que leva o tempo necessário para explorar situações complexas em profundidade, e de disciplinas nas quais o ritmo de publicação inclui grandes obras elaboradas em longos períodos de tempo. Precisamos assegurar que nossos regimes de financiamento e estruturas institucionais tenham algum espaço para esse tipo de trabalho. Na prática, o advento da Internet às vezes pode facilitar envolvimentos de longo prazo apesar das restrições do tempo de pesquisa - mesmo não sendo possível estar em um campo físico o tempo todo, muitas vezes agora se pode permanecer em contato virtual e encaixar algumas formas de envolvimento etnográfico nas brechas entre outras atividades. Aprendi muito a esse respeito no início deste ano quando conheci um grupo de antropólogos da Universidade de Aarhus (organizado por Nanna Schneidermann e Elizabeth Williams Ørberg) que estavam usando o Facebook de várias maneiras entrelaçadas com encontros face a face em seu trabalho de campo. Precisamos ser um pouquinho criativos em nossos modelos do que é a etnografia para acompanhar tanto os padrões mutáveis de conexão e envolvimento que encontramos quanto as restrições que nos são impostas... mas concordo que mesmo assim devemos frisar a importância de, às vezes, dedicar longos períodos de tempo e ter experiências aprofundadas no âmbito da teoria.

Adriana Braga: Como você enfoca a questão da presença do pesquisador no setting etnográfico em uma etnografia virtual? Acha que é possível conceber como "etnográfica" uma pesquisa baseada exclusivamente em dados online?

Christine Hine: Acho que a pesquisa baseada apenas em dados online pode ser etnográfica, desde que seja focada na experiência de navegação do/a etnógrafo/a nesse setting. Essa pesquisa pode tornar-se autoetnográfica, $e$ acho que é útil aplicar à Internet esse modelo, que nos diz coisas interessantes sobre o modo como incorporamos o uso da Internet a experiências sociais significativas. Contudo, a maioria dos projetos sairia ganhando se, em algum momento, houvesse envolvimento com as experiências de outras pessoas, expondo as interpretações do etnógrafo a serem questionadas por outros. Isto ainda pode acontecer via comunicação online, mas não é algo que se possa fazer apenas examinando atentamente textos arquivados. Acho que a 
etnografia geralmente implica alguma forma de envolvimento em tempo real.

Adriana Braga: Você pode nos falar sobre seus atuais interesses e projetos de pesquisa?

Christine Hine: Com base no que contei acima, algumas coisas que fiz recentemente não foram tão etnográficas. Tenho tratado de discussões online sobre paternidade/maternidade, vendo como implementam formas particulares de perícia, e o tipo de demonstração de que são bons pais/mães que constroem. Na verdade, esta é só uma análise de textos já arquivados, mas espero no futuro poder fazer pesquisas um pouco mais etnográficas em settings cotidianos, estudando o modo como as pessoas localizam e consomem conselhos sobre paternidade/ maternidade. Também estou interessada em redes como Freecycle, que permite que as pessoas troquem seus pertences que não querem mais com outras pessoas que moram na mesma área. Este website é muito interessante, porque entremescla constantemente interações online e face a face, e é muito difícil de circunscrever metodologicamente falando. Por fim, estou interessada no entrelaçamento de mídia de massa e mídia online, em investigar como tanto a televisão quanto os jornais representam a Internet e são representados na Internet. A maior parte do que faço ainda pode ser capturada por uma pergunta muito geral: "O que as pessoas acham que estão fazendo quando usam a Internet?". 
Ethnography according to Christine Hine: naturalistic approach to digital environments

\section{Abstract}

Christine Hine is an English scientist, who teaches and researches at the University of Surrey, England. She has a strong interdisciplinary approach (ranging from Biology to Information Science and Communications), focusing on research methodologies applied to online environments. In Brazil, she is best known for her books Virtual Ethnography (Sage, 2000) and Virtual Methods (Berg, 2005). In this interview, Christine Hine tells about her career and influences, as well as ethnographic methodologies applied to online environments and some of her current research subjects.

\section{Keywords}

Ethnography. Methodology. Internet.

\section{Etnografía según Christine Hine: abordaje naturalística para ambientes digitales}

\section{Resumen}

Christine Hine es uma científica inglesa, profesora y investigadora en la Universidad de Surrey, Inglaterra. Ella tiene fuerte orientación interdisciplinar (de la Biologia hasta las Ciências de la Información y Comunicación), y es una autora de referéncia en las metodologías de investigación en ambientes virtuales. En Brazil, ella es conocida por sus libros Virtual Ethnography (Sage, 2000) y Virtual Methods (Berg, 2005). En esta entrevista exclusiva, Hine habla de su carrera y influéncias, de las metodologías etnográficas aplicadas a ambientes virtuales, bien como de sus proyectos actuales.

\section{Palabras-clave}

Etnografia. Metodologia. Internet 


\section{Expediente}

A revista E-Compós é a publicação científica em formato eletrônico da Associação Nacional dos Programas de Pós-Graduação em Comunicação (Compós). Lançada em 2004, tem como principal finalidade difundir a produção acadêmica de pesquisadores da área de Comunicação, inseridos em instituições do Brasil e do exterior.
E-COMPÓS I www.e-compos.org.br I E-ISSN 1808-2599

Revista da Associação Nacional dos Programas de Pós-Graduação em Comunicação.

E-compós, Brasília, v.15, n.3, set./dez. 2012.

A identificação das edições, a partir de 2008 passa a ser volume anual com três números.

\section{CONSELHO EDITORIAL}

Afonso Albuquerque, Universidade Federal Fluminense, Brasil Alberto Carlos Augusto Klein, Universidade Estadual de Londrina, Brasil Álvaro Larangeira, Universidade Tuiuti do Paraná, Brasil André Luiz Martins Lemos, Universidade Federal da Bahia, Brasil Ângela Freire Prysthon, Universidade Federal de Pernambuco, Brasil Angela Cristina Salgueiro Marques, Faculdade Cásper Líbero (São Paulo), Brasil Antonio Roberto Chiachiri Filho, Faculdade Cásper Líbero, Brasil Arthur Autran Franco de Sá Neto, Universidade Federal de São Carlos, Brasi Benjamim Picado, Universidade Federal Fluminense, Brasil César Geraldo Guimarães, Universidade Federal de Minas Gerais, Brasil Cristiane Freitas Gutfreind, Pontifícia Universidade Católica do Rio Grande do Sul, Brasil

Denilson Lopes, Universidade Federal do Rio de Janeiro, Brasil Eduardo Peñuela Cañizal, Universidade Paulista, Brasil

Eduardo Vicente, Universidade de São Paulo, Brasil

Eneus Trindade, Universidade de São Paulo, Brasil

Erick Felinto de Oliveira, Universidade do Estado do Rio de Janeiro, Brasil Florence Dravet, Universidade Católica de Brasília, Brasil Gelson Santana, Universidade Anhembi/Morumbi, Brasil Gislene da Silva, Universidade Federal de Santa Catarina, Brasil Guillermo Orozco Gómez, Universidad de Guadalajara Gustavo Daudt Fischer, Universidade do Vale do Rio dos Sinos, Brasil Hector Ospina, Universidad de Manizales, Colômbia Herom Vargas, Universidade Municipal de São Caetano do Sul, Brasil Inês Vitorino, Universidade Federal do Ceará, Brasil Jay David Bolter, Georgia Institute of Technology Jeder Silveira Janotti Junior, Universidade Federal de Pernambuco, Brasil John DH Downing, University of Texas at Austin, Estados Unidos José Afonso da Silva Junior, Universidade Federal de Pernambuco, Brasil José Carlos Rodrigues, Pontifícia Universidade Católica do Rio de Janeiro, Brasil José Luiz Aidar Prado, Pontifícia Universidade Católica de São Paulo, Brasil Kelly Cristina de Souza Prudêncio, Universidade Federal do Paraná, Brasil.
Laan Mendes Barros, Universidade Metodista de São Paulo, Brasil Lance Strate, Fordham University, USA, Estados Unidos Lorraine Leu, University of Bristol, Grã-Bretanha Lucia Leão, Pontifícia Universidade Católica de São Paulo, Brasil Malena Segura Contrera, Universidade Paulista, Brasil

Márcio de Vasconcellos Serelle, Pontifícia Universidade Católica de Minas Gerais, Brasil

Maria Aparecida Baccega, Universidade de São Paulo e Escola Superior de Propaganda e Marketing, Brasil

Maria Ataide Malcher, Universidade Federal do Pará, Brasil

Maria das Graças Pinto Coelho, Universidade Federal do Rio Grande do Norte, Brasil Maria Immacolata Vassallo de Lopes, Universidade de São Paulo, Brasil Maria Luiza Martins de Mendonça, Universidade Federal de Goiás, Brasi Mauro de Souza Ventura, Universidade Estadual Paulista, Brasil Mauro Pereira Porto, Tulane University, Estados Unidos Mirna Feitoza Pereira, Universidade Federal do Amazonas, Brasil Nilda Aparecida Jacks, Universidade Federal do Rio Grande do Sul, Brasil Osvando J. de Morais, Universidade de Sorocaba, Brasil Potiguara Mendes Silveira Jr, Universidade Federal de Juiz de Fora, Brasil Renato Cordeiro Gomes, Pontifícia Universidade Católica do Rio de Janeiro, Brasil Robert K Logan, University of Toronto, Canadá

Ronaldo George Helal, Universidade do Estado do Rio de Janeiro, Brasil Rose Melo Rocha, Escola Superior de Propaganda e Marketing, Brasil Rossana Reguillo, Instituto de Estudos Superiores do Ocidente, Mexico Rousiley Celi Moreira Maia, Universidade Federal de Minas Gerais, Brasil Sebastião Guilherme Albano da Costa, Universidade Federal do Rio Grande do Norte, Brasil

Simone Maria Andrade Pereira de Sá, Universidade Federal Fluminense, Brasil Tiago Quiroga Fausto Neto, Universidade de Brasília, Brasil Suzete Venturelli, Universidade de Brasília, Brasil Valerio Fuenzalida Fernández, Puc-Chile, Chile Veneza Mayora Ronsini, Universidade Federal de Santa Maria, Brasi Vera Regina Veiga França, Universidade Federal de Minas Gerais, Brasil

\section{COMISSÃO EDITORIAL}

Adriana Braga I Pontifícia Universidade Católica do Rio de Janeiro, Brasil Felipe Costa Trotta I Universidade Federal Fluminense, Brasil

\section{CONSULTORES AD HOC}

Ana Carolina Escosteguy, Pontifícia Universidade Católica do Rio Grande do Sul, Brasil Bruno Campanella, Universidade Federal Fluminense, Brasil

Edison Gastaldo, Universidade Federal Rural do Rio de Janeiro, Brasil Elizabeth Duarte, Universidade Federal de Santa Maria, Brasil Roseli Figaro, Universidade de São Paulo, Brasil

EDIÇ̃̃O DE TEXTO E RESUMOS I Susane Barros

SECRETÁRIA EXECUTIVA I Juliana Depiné

EDITORAÇÃo ELETRÔNICA I Roka Estúdio

TRADUÇ̃̃o I Sieni Campos e Markus Hediger
COMPÓS I www.compos.org.br

Associação Nacional dos Programas de Pós-Graduação em Comunicação

Presidente

Julio Pinto

Pontifícia Universidade Católica de Minas Gerais, Brasil juliopinto@pucminas.br

Vice-presidente

Itania Maria Mota Gomes

Universidade Federal da Bahia, Brasil

itania@ufba.br

Secretária-Geral

Inês Vitorino

Universidade Federal do Ceará, Brasil

inesvic@gmail.com 